\title{
Transmission of Fusarium oxysporum f. sp. fragariae Through Stolons in Strawberry Plants
}

\author{
A. M. Pastrana, D. C. Watson, and T. R. Gordon ${ }^{\dagger}$ \\ Department of Plant Pathology, University of California, Davis, CA 95616.
}

\begin{abstract}
Fusarium wilt of strawberry, caused by the soilborne pathogen Fusarium oxysporum f. sp. fragariae, is a growing threat to the strawberry industry worldwide. Symptoms of the disease typically include stunting, wilting, crown discoloration, and eventual plant death. When Fusarium wilt was discovered in California, the disease was not known to occur anywhere else in North America. Long distance movement of the pathogen would most likely occur through transport of infected plants, which seems plausible if strawberry plants can sustain infections without showing symptoms of disease. The results of this study document that $F$. oxysporum

f. sp. fragariae can move through stolons of infected mother plants and colonize first-generation daughter plants. The pathogen can also move through stolons from first to second-generation daughter plants. Daughter plants of both generations were always symptomless. The pathogen was recovered from both roots and petioles of infected daughter plants. Similar results were obtained for two cultivars known to be susceptible to Fusarium wilt, Albion and Monterey. Transmission through stolons from mother to daughter plants also occurred in the resistant cultivar, San Andreas, but less frequently than in Albion and Monterey.
\end{abstract}

California is home to the largest strawberry (Fragaria $\times$ ananassa) production regions in the United States, comprising a $\$ 1.86$ billion industry and accounting for $80 \%$ of national strawberry fruit production. As the state's tenth largest agricultural export, these sales were valued at $\$ 390$ million in 2015 (California Department of Food and Agriculture 2016). Moreover, California is the nation's top producer of strawberry transplants. In a given year, high-elevation nurseries in northern California produce over 800 million transplants valued at approximately $\$ 95$ million. These transplants are used to establish fruit production fields in California and are also exported, mainly to Mexico, Canada, Spain, Portugal, and Argentina (M. MeyerJertberg, personal communication).

Strawberry nurseries typically use preplant fumigation to suppress soilborne pathogens, and quality control ensures that only vigorous crowns that appear healthy are shipped to fruit producers. However, various factors may allow nursery plants to become infected, and where infections remain cryptic, plants can serve as vehicles for delivery of pathogens to fruit production fields. For example, Verticillium dahliae, cause of Verticillium wilt, can be transmitted from mother to daughter plants, with the latter remaining symptomless (Gordon et al. 2002). Like V. dahliae, Fusarium oxysporum f. sp. fragariae is a wilt pathogen with the capacity to move through the $x y-$ lem and establish a systemic infection. This suggests the possibility that the causal agent of Fusarium wilt in strawberries may reside in symptomless daughter plants.

Symptoms of Fusarium wilt typically include stunting, reduced productivity, necrosis and drying of leaves and petioles, crown discoloration, and eventual collapse and plant death (Koike and Gordon 2015). Since its discovery in 1962 in Queensland, Australia (Golzar et al. 2007; Winks and Williams 1965), F. oxysporum f. sp. fragariae has been reported to affect strawberry production in many locations

${ }^{\dagger}$ Corresponding author: T. R. Gordon; trgordon@ucdavis.edu

A. M. Pastrana and D. C. Watson contributed equally to this work.

Funding: This research was carried out with financial support from the California Strawberry Commission and the USDA National Institute of Food and Agriculture through Hatch project CA-D-PPA-6699-H.

Accepted for publication 16 November 2018.

(c) 2019 The American Phytopathological Society throughout the world (Koike and Gordon 2015). In California, diseased plants were first observed in Ventura and Santa Barbara counties in 2006, and since that time, the disease has become established in every major strawberry production area of the state (Koike et al. 2009).

The emergence of Fusarium wilt in California followed a ban on methyl bromide, a key ingredient in fumigant mixtures, and changes in application methods that resulted in incomplete treatment of the soil (Gordon et al. 2016). This allowed inoculum already present to increase to damaging levels. Once established in a field, there are limited options for management of Fusarium wilt (Koike and Gordon 2015). Consequently, it is important to avoid introducing the pathogen to new locations, which necessitates exclusive use of pathogen-free nursery plants.

The present study was undertaken to investigate the potential for symptomless infections to become established during propagation of strawberry cultivars grown in California. The specific objectives were to 1 ) determine if $F$. oxysporum $\mathrm{f}$. sp. fragariae can move through stolons from mother to daughter plants, 2) determine if infected daughter plants manifest symptoms of Fusarium wilt, and 3) assess distribution of the pathogen within daughter plants.

\section{Materials and Methods}

Plant material. Cultivars Albion, Monterey, and San Andreas were obtained from a low elevation nursery and maintained at $-2{ }^{\circ} \mathrm{C}$ prior to use. Ten percent of plants from the batch used in our experiments was assayed for the presence of $F$. oxysporum f. sp. fragariae by culturing tissue on Komada's selective medium (Komada 1975), as described by Henry et al. (2017). The pathogen was not recovered from any of the tested plants. Ten commercial transplants (= replications) of each cultivar were placed in $15 \mathrm{~cm}$ diameter pots filled with Sunshine Mix \#1 (Sun Gro Horticulture, Canada). Pots were placed in randomly assigned positions in a greenhouse and allowed to grow for 2 weeks before inoculation. Daughter plants were placed in new pots near to their mother plants. Plants were supplied with deionized water as needed for the first month, and thereafter, plants were watered weekly with Calcinit solution ( $1 \%$ ammoniacal nitrogen, $14.5 \%$ nitrate, and $19 \%$ calcium).

Inoculations. To obtain inoculum, a known pathogenic isolate of F. oxysporum f. sp. fragariae (GL1080, originating from Ventura County, CA) (Henry et al. 2017) was grown on potato dextrose agar (PDA) under continuous fluorescent light at room temperature. A spore suspension was prepared from fully colonized PDA plates, as described by Schmale and Gordon (2003), and adjusted to $10^{5}$ 
spores per $\mathrm{ml}$ in $0.1 \%$ water agar. Ten milliliters of inoculum were introduced into the soil at five locations around each plant using a pipette (total volume $=50 \mathrm{ml}$ ). At each location, inoculum was placed at a depth of approximately $6 \mathrm{~cm}$. A second inoculation was carried out 1 week later using the same procedure.

The first experiment was conducted twice between October 2016 and March 2017, and included the cultivars Albion and Monterey, which are known to be susceptible to Fusarium wilt. Plants were maintained in a greenhouse, wherein temperatures ranged from 11 to $21^{\circ} \mathrm{C}$ and humidity was between 18 and $78 \%$.

The second experiment was conducted twice between June and December of 2017, with San Andreas, a cultivar known to be resistant to Fusarium wilt. During these experiments, temperatures ranged from 17 to $33^{\circ} \mathrm{C}$ and humidity was between 18 and $78 \%$.

Data collection. At the end of each experiment, plants and stolons were tagged to identify their generation and disease symptoms were recorded. Mother plants and first-generation stolons were collected 90 days after the second inoculation. By this time, daughter plants were well established and growing independently of mother plants. First-generation daughters and second-generation stolons were collected 104 days postinoculation, and second-generation daughters were collected 118 days postinoculation. Stolons produced by second daughters were removed weekly and not included in the study. Across both experiments, 86 daughter plants, consisting of 41 first-generation and $45 \mathrm{~s}$-generation daughters, along with 94 stolons (= 47 first-generation +47 s-generation) of Albion were assayed. For Monterey, 106 daughter plants, consisting of 46 firstgeneration and $60 \mathrm{~s}$-generation daughters, and 110 stolons $(=46$ first-generation +64 s-generation) were assayed. For San Andreas, 181 daughter plants ( $=74$ first-generation +107 s-generation $)$ and 190 stolons (= 76 first-generation +114 s-generation) were assayed. In total, isolations were attempted for 60 mother plants, 373 daughter plants, and 394 stolons. Crowns, petioles, and stolons of mother plants, and crowns, petioles, stolons (first daughters only), and roots of daughter plants were collected. Segments of approximately 1 to $2 \mathrm{~cm}$ taken from the beginning, middle, and end of each stolon were assayed individually. Crowns were cut longitudinally in half, and three pieces of approximately $0.5 \mathrm{~cm}^{2}$ were removed from each half. In addition, six petioles and eight root segments (1 to $2 \mathrm{~cm}$ in length) were assayed from each daughter plant. Segments were taken from the middle of each petiole and from the upper portion of the roots, near the crown. Crown, petiole, and stolon pieces were rinsed with $0.1 \%$ Tween 20 , followed by immersion in $70 \%$ ethanol for $20 \mathrm{~s}$ and $1 \%$ sodium hypochlorite for $60 \mathrm{~s}$. Root samples were rinsed in $0.1 \%$ Tween 20 , then immersed in $1 \%$ sodium hypochlorite for $20 \mathrm{~s}$ followed by $10 \mathrm{~s}$ in sterile distilled water. All tissue samples were placed on Komada's selective medium for 7 to 10 days at room temperature under continuous fluorescent light. Most colonies were identified as $F$. oxysporum f. sp. fragariae based on morphological criteria, but ambiguous colonies were subjected to a PCR test using diagnostic primers and protocol developed by Suga et al. (2013).

Data analysis. Data were expressed as the proportion of each tissue type found to be infected, including only stolons and plants originating from a mother plant that was confirmed to be infected. For second-generation daughter plants, the infection proportion was also calculated based only on plants originating from an infected firstgeneration daughter. For each infected daughter plant (crowns were confirmed to be infected by $F$. oxysporum f. sp. fragariae), the proportion of petioles and root segments also found to be infected was calculated. Prior to statistical analysis, proportions were subjected to an arcsine square root transformation. Analysis of variance (ANOVA) was performed using the $\mathrm{R}$ programming language (version 3.0.3). Where treatment effects were significant $(P \leq 0.050)$, Tukey's all pairwise comparison test was used to determine which means were significantly different between tissue types (first stolon, first daughter, second stolon, and second daughter). Results based on nontransformed data are presented. Differences between the proportion of infected root and petiole samples from infected daughter plants were assessed using a chi-square test $(P \leq 0.050)$.

\section{Results}

All plants remained healthy during the experiment and no symptoms of Fusarium wilt were observed on mother or daughter plants. One mother plant of the cultivar Albion and one of Monterey were not infected by $F$. oxysporum $\mathrm{f}$. sp. fragariae, so plants and stolons originating from them were excluded. Plants and stolons were scored as infected if the pathogen was recovered from any of the assayed segments. ANOVA was used to determine if cultivar was a significant source of variation in frequency of colonization of each tissue type. The experiment $\times$ cultivar interaction was not significant in any case $(P \geq 0.072)$, and so data were pooled across experiments to test the significance of cultivar as a source of variation in infection frequency. There was no significant difference in infection rate between cultivars Albion and Monterey for any of the tissues assayed $(P>0.167)$.

For each cultivar, ANOVA was used to test for differences in frequency of infection between first and second-generation stolons, and between first and second-generation daughter plants. For Albion, $59.6 \%$ of first-generation stolons were infected (28/47), whereas the infection rate for second-generation stolons was significantly lower at $23.4 \%(11 / 47)(P=0.035)$. First- and second-generation daughter plant infection rates were $40.0 \%$ (16/40) and $18.6 \%(8 /$ $43)$, respectively, with no significant difference between generations $(P=0.499)$ (Table 1). Similar results were obtained for Monterey, with first-generation stolons infected at a significantly higher frequency than second-generation stolons $(P=0.032)$, and a higher but not significantly different rate of infection in first than in second-generation daughters $(P=0.116)$ (Table 1$)$.

Of 20 inoculated mother plants of San Andreas, 15 were confirmed to be infected. Based on these 15 plants, $40.0 \%$ (23/59) of firstgeneration stolons were infected, while the infection rate for second-generation stolons was significantly lower at $8.5 \%(8 / 94)$ $(P=0.013)$. First- and second-generation daughter plant infection rates were $19.0 \%(11 / 58)$ and $4.5 \%$ (4/89), respectively, with no significant difference between generations $(P=0.196)$ (Table 1).

The rate of transmission from infected first daughters to secondgeneration daughters $(47.1 \%$ and $22.2 \%)$ was higher than the rate of transmission from mothers to first daughters (40.0\% and $18.8 \%$ ) for both Albion and San Andreas respectively, but in neither case was the difference significant $(P \geq 0.080)$. For Monterey, the transmission rate from first to second daughters $(29.0 \%)$ was lower than the transmission rate from mother to first daughter $(43.5 \%)$, but here again the difference was not significant $(P=0.581)$.

For Albion and Monterey, infections of first and secondgeneration daughter plants extended into both roots and petioles, without a significant difference in frequency of infection between the two tissue types for either generation of either cultivar $\left(\chi^{2}>\right.$ $0.045,1 \mathrm{df}, P>0.247)$. For first-generation daughters of San Andreas, only roots were infected, but in second-generation daughters, the pathogen was recovered from both roots and petioles (Fig. 1). A $\chi^{2}$ test indicated there was no significant difference in the infection rate of roots and petioles $\left(\chi^{2}>0.389,1 \mathrm{df}, P>0.166\right)$.

\section{Discussion}

Fusarium wilt was recognized as the cause of collapsing strawberry plants in California in 2006 (Koike et al. 2009). Genetic

Table 1. Percentage of stolons and daughter plants of strawberry cultivars Albion, Monterey, and San Andreas colonized by Fusarium oxysporum f. sp. fragariae $^{\mathrm{y}}$

\begin{tabular}{llll}
\hline & \multicolumn{1}{c}{ Albion $^{\mathbf{z}}$} & \multicolumn{1}{c}{ Monterey $^{\mathbf{z}}$} & \multicolumn{1}{c}{ San Andreas $^{\mathbf{z}}$} \\
\hline First stolon & $59.6 \%(28 / 47) \mathrm{a}$ & $50.0 \%(23 / 46) \mathrm{a}$ & $38.9 \%(23 / 59) \mathrm{a}$ \\
First daughter & $40.0 \%(16 / 40) \mathrm{ab}$ & $43.5 \%(20 / 46) \mathrm{ab}$ & $18.9 \%(11 / 58) \mathrm{ab}$ \\
Second stolon & $23.4 \%(11 / 47) \mathrm{b}$ & $21.9 \%(14 / 64) \mathrm{b}$ & $8.5 \%(8 / 94) \mathrm{b}$ \\
Second daughter & $18.6 \%(8 / 43) \mathrm{b}$ & $15.0 \%(9 / 60) \mathrm{b}$ & $5.5 \%(4 / 89) \mathrm{b}$ \\
\hline
\end{tabular}

y Strawberry cultivars Albion and Monterey are susceptible to Fusarium wilt; San Andreas is resistant.

${ }^{\mathrm{z}}$ Mean infection percentages in the same column followed by a common letter are not significantly different according to Tukey's honestly significant difference (HSD) test at $P=0.05$. 


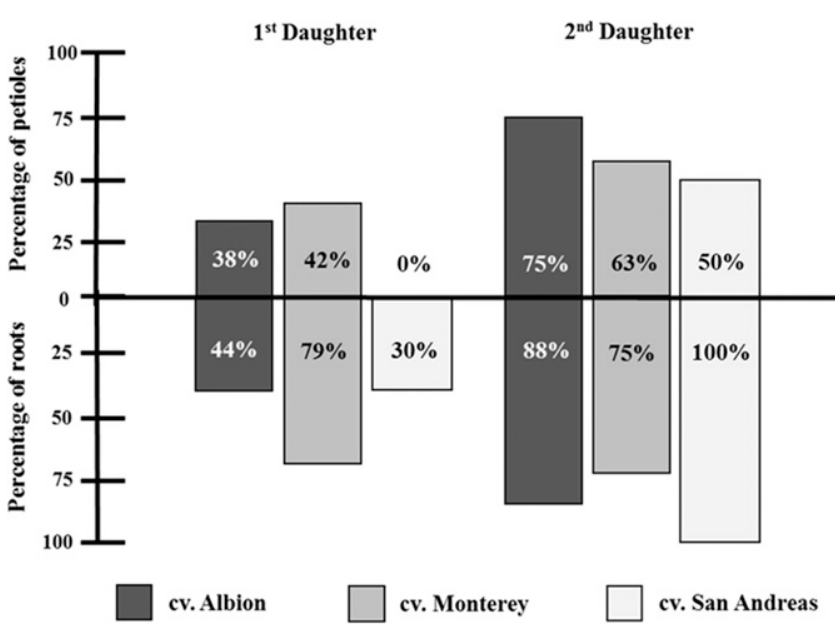

Fig. 1. Each bar represents the percentage of petioles and root tissues on infected daughter plants that were colonized by Fusarium oxysporum f. sp. fragariae.

similarities between isolates of $F$. oxysporum $\mathrm{f}$. sp. fragariae in California and those in countries where the pathogen is of long residence (Henry et al. 2017) implied that one or more of them could be a source of the infestation found in California. The most plausible means by which $F$. oxysporum $\mathrm{f}$. sp. fragariae could be moved between continents would be through transport of infected plants, which seems unlikely to occur if plants show symptoms of Fusarium wilt.

Nam et al. (2011) reported that colonization of strawberry cultivar Kumhyang by $F$. oxysporum $\mathrm{f}$. sp. fragariae extended into stolons and first-generation daughter plants. Consistent with those findings, our results show that infections of the susceptible cultivars Albion and Monterey result in colonization of stolons, which can reach both first and second-generation daughters. Infection rates trended lower across generations in both cultivars, but differences between first and second-generation daughters were not significant $(P \geq 0.116)$. Because both Albion and Monterey are susceptible to Fusarium wilt, the intensity of infection must not be so severe as to reduce vigor below the point where stolons and daughters can be produced. Although an experimental protocol was developed that achieved this, it cannot be determined how commonly such infections would occur in a strawberry nursery.

The strawberry cultivar San Andreas has been confirmed to be resistant to Fusarium wilt through controlled inoculations (Gordon et al. 2016), and resistance appears to be conferred by a single dominant gene (Pincot et al. 2018). It was therefore not expected that inoculated plants would sustain systemic infections that extended into stolons and daughter plants. However, San Andreas did transmit $F$. oxysporum f. sp. fragariae to first and second-generation daughters, and because this cultivar does not suffer visible damage from Fusarium wilt, transmission to daughter plants may be more likely to occur in San Andreas under field conditions than in cultivars that are susceptible to the disease.

The findings of this study are similar to those reported for Verticillium wilt of strawberry (Gordon et al. 2002). In that case, transmission through stolons appeared to be the primary means by which daughter plants became infected, even when they were rooted in infested soil. Although symptoms of Verticillium wilt commonly developed in mother plants, they would likely remain undetected in a visual survey owing to overgrowth by vigorous daughters, which showed no symptoms of disease (Gordon et al. 2002). Likewise, the required visual inspections may fail to detect the presence of
F. oxysporum f. sp. fragariae in nursery plantings because infected daughter plants can remain symptomless.

It is noteworthy that infections of daughter plants were not limited to petioles but also extended into the roots of all three cultivars. It is not known if the pathogen is present in roots only as spores or if spores germinate and growth extends beyond the xylem. In any case, the presence of $F$. oxysporum $\mathrm{f}$. sp. fragariae in roots may facilitate establishment of an inoculum reservoir in soil, increasing the risk of infection in subsequent crops.

Infection of strawberry plants by $F$. oxysporum $\mathrm{f}$. sp. fragariae is not likely to occur in nurseries where production practices include annual preplant fumigation with a mix including chloropicrin and methyl bromide. When methyl bromide is no longer available to nursery operators, the risk of cryptic infections by the Fusarium wilt pathogen will increase. However, some risk remains even where methyl bromide is used, if fumigations are applied when conditions of temperature and soil moisture are not optimal. Although molecular tests are available for detection of the pathogen, given that hundreds of millions of plants are produced by California nurseries annually, no practical sampling scheme can ensure that infected plants do not escape detection. Consequently, prevention of infection in nurseries, through proper sanitation measures and effective preplant fumigation, is the only means available to ensure that cryptically infected plants are not shipped to fruit production fields.

\section{Acknowledgments}

The authors gratefully acknowledge Sierra Cascade Nursery for providing plant material, and Robert Farr, S. Johnson, J. Durias, Neville Mathews, Katherine Young, and A. Syed for valuable technical assistance.

\section{Literature Cited}

California Department of Food and Agriculture. 2016. California Agricultural Statistics Review. Accessed on May $26^{\text {th }}, 2018$ from https://www.cdfa.ca. gov/Statistics/PDFs/2016Report.pdf

Golzar, H., Phillips, D., and Mack, S. 2007. Occurrence of strawberry root and crown rot in Western Australia. Australas. Plant Dis. Notes 2:145-147.

Gordon, T. R., Daugovish, O., Koike, S. T., Islas, C. M., Kirkpatrick, S. C. Yoshisato, J. A., and Shaw, D. V. 2016. Options for Management of Fusarium Wilt of Strawberry in California. Int. J. Fruit Sci. 16(sup1): 160-168.

Gordon, T. R., Kirkpatrick, S. C., Shaw, D. V., and Larson, K. D. 2002 Differential infection of mother and runner plant generations by Verticillium dahliae in a high elevation strawberry nursery. HortScience 37:927-931.

Henry, P. M., Kirkpatrick, S. C., Islas, C. M., Pastrana, A. M., Yoshisato, J. A., Koike, S. T., Daugovish, O., and Gordon, T. R. 2017. The population of Fusarium oxysporum f. sp. fragariae, cause of Fusarium wilt of strawberry, in California. Plant Dis. 101:550-556.

Koike, S. T., and Gordon, T. R. 2015. Management of Fusarium wilt of strawberry. Crop Prot. 73:67-72.

Koike, S. T., Kirkpatrick, S. C., and Gordon, T. R. 2009. Fusarium wilt of strawberry caused by Fusarium oxysporum in California. Plant Dis. 93: 1077.

Komada, H. 1975. Development of a selective medium for quantitative isolation of Fusarium oxysporum from natural soils. Rev. Plant Prot. Res. 8:114-125.

Nam, M. H., Kang, Y. J., Lee, I. H., Kim, H. G., and Chun, C. 2011. Infection of daughter plants by Fusarium oxysporum f. sp. fragariae through runner propagation of strawberry. Korean J. Hort. Sci. Technol. 29:273-277.

Pincot, D. D. A., Poorten, T. J., Hardigan, M. A., Harshman, J. M., Acharya, C. B., Cole, G. S., Gordon, T. R., Stueven, M., Edger, P. P., and Knapp, S. J. 2018. Genome-wide association mapping uncovers Fw1, a dominant gene conferring resistance to Fusarium wilt in strawberry. G3 Genes Genom Genet. 8:1817-1828.

Schmale, D. G., and Gordon, T. R. 2003. Variation in susceptibility to pitch canker disease, caused by Fusarium circinatum, in native stands of Pinus muricata. Plant Pathol. 52:720-725.

Suga, H., Hirayama, Y., Morishima, M., Suzuki, T., Kageyama, K., and Hyakumachi, M. 2013. Development of PCR primers to identify Fusarium oxysporum f. sp. fragariae. Plant Dis. 97:619-625.

Winks, B. L., and Williams, Y. N. 1965. A wilt of strawberry caused by a new form of Fusarium oxysporum. Queensl. J. Agric. Anim. Sci 22:475-479. 